\title{
Nonsurgical Treatment of Acetabular Labral Tears
}

\author{
Melissa Theige and Shannon David
}

\begin{abstract}
Clinical Scenario: Surgical treatment of acetabular labral tears has been explored in multiple studies, while there is a lack of research on the effectiveness of conservative methods. Focused Clinical Question: To what extent can nonsurgical treatment produce symptomatic or functional improvements in athletes with an acetabular labral tear? Summary of Search, Best Evidence Appraised, and Key Findings: The literature was searched for studies of patients with confirmed acetabular labral tears who participated in any level of sport. Four studies were located, all of which were included. Clinical Bottom Line: The research discussed in this review agreed that conservative management of acetabular labral tears produced measurable improvements in pain and function among the athletes studied, including their ability to participate in sport activities. Based on these findings, it appears that conservative management is effective at rehabilitating athletes with acetabular labral tears. However, this method should not be applied to every athlete based on the low strength of current research. Treatment plans should be decided upon on a case-by-case basis. Strength of Recommendation: The studies located were of low quality. The highest Oxford Center for Evidence-Based Medicine Level of Evidence achieved was 4 . Higher level studies must be conducted before the conclusions of this research can be applied clinically with assertion. Strength of recommendation is level 3.
\end{abstract}

Keywords: rehabilitation, hip, acetabular labral tear, nonsurgical, conservative management

\section{Clinical Scenario}

Although there are multiple published studies regarding the surgical treatment of acetabular labral tears, little research has been conducted regarding nonsurgical methods. ${ }^{1-5}$ Although the primary source of labral tears is believed to be bony femoroacetabular impingement, it has been hypothesized that hip instability and poor neuromuscular control can replicate or exacerbate this mechanism of injury. ${ }^{6}$ It stands to reason, then, that rehabilitation could address these deficits and improve symptoms, allowing patients to postpone or forgo surgical treatment. Furthermore, orthopedic surgeons frequently recommend or require conservative management of acetabular labral tears before performing surgery, and this recommendation should be made using evidence-based practice. ${ }^{7}$ Finally, for the athlete who cannot or does not wish to undergo surgery, it is important to determine what outcomes are feasible through conservative management alone.

\section{Focused Clinical Question}

To what extent can nonsurgical treatment produce symptomatic or functional improvements in athletes with an acetabular labral tear?

\section{Summary of Search, Best Evidence Appraised, and Key Findings}

A search of the literature was conducted to locate research addressing nonsurgical treatment of acetabular labral tears in athletes of any level (Figure 1). The search produced a limited number of relevant articles: 3 case reports and 1 case series. In each study, researchers used highly customized physical therapy protocols to address biomechanical abnormalities in each individual patient. These exercises were sometimes used in conjunction with other

Theige is with the Pingree School, Hamilton, MA. David is with Health, Nutrition, and Exercise Sciences, North Dakota State University, Fargo, ND. Theige (mtheigerichie@gmail.com) is corresponding author. nonsurgical therapies, such as ice and instrument-assisted soft tissue mobilization. Nonsurgical therapy of acetabular labral tears reduced pain in all cases and facilitated return to some level of sport, up to and including professional, for all athletes for whom that outcome was reported. Other measures of function, such as Lequesne Hip Score and Nonarthritic Hip Score, also improved in all cases.

\section{Clinical Bottom Line}

The research discussed in this review agreed that conservative management of acetabular labral tears produced meaningful improvements in pain and function among the athletes studied, including their ability to participate in multiple levels of sport. Based on these findings, it appears that conservative management is effective at rehabilitating some athletes with acetabular labral tears. However, this method should not be applied to every athlete based on the low strength of current research. Treatment plans should be decided upon on a case-by-case basis.

\section{Strength of Recommendation}

The studies located were of low quality. The highest Oxford Center for Evidence-Based Medicine Level of Evidence achieved was 4. Higher level studies must be conducted before the conclusions of this research can be applied clinically with assertion. Strength of recommendation is level 3 .

\section{Search Strategy}

The search strategy used is depicted by a flow diagram in Figure 1.

\section{Results of Search}

The initial search produced over 40 results. Following the application of the eligibility criteria, 4 studies remained for review. Table 1 presents a summary of results. 


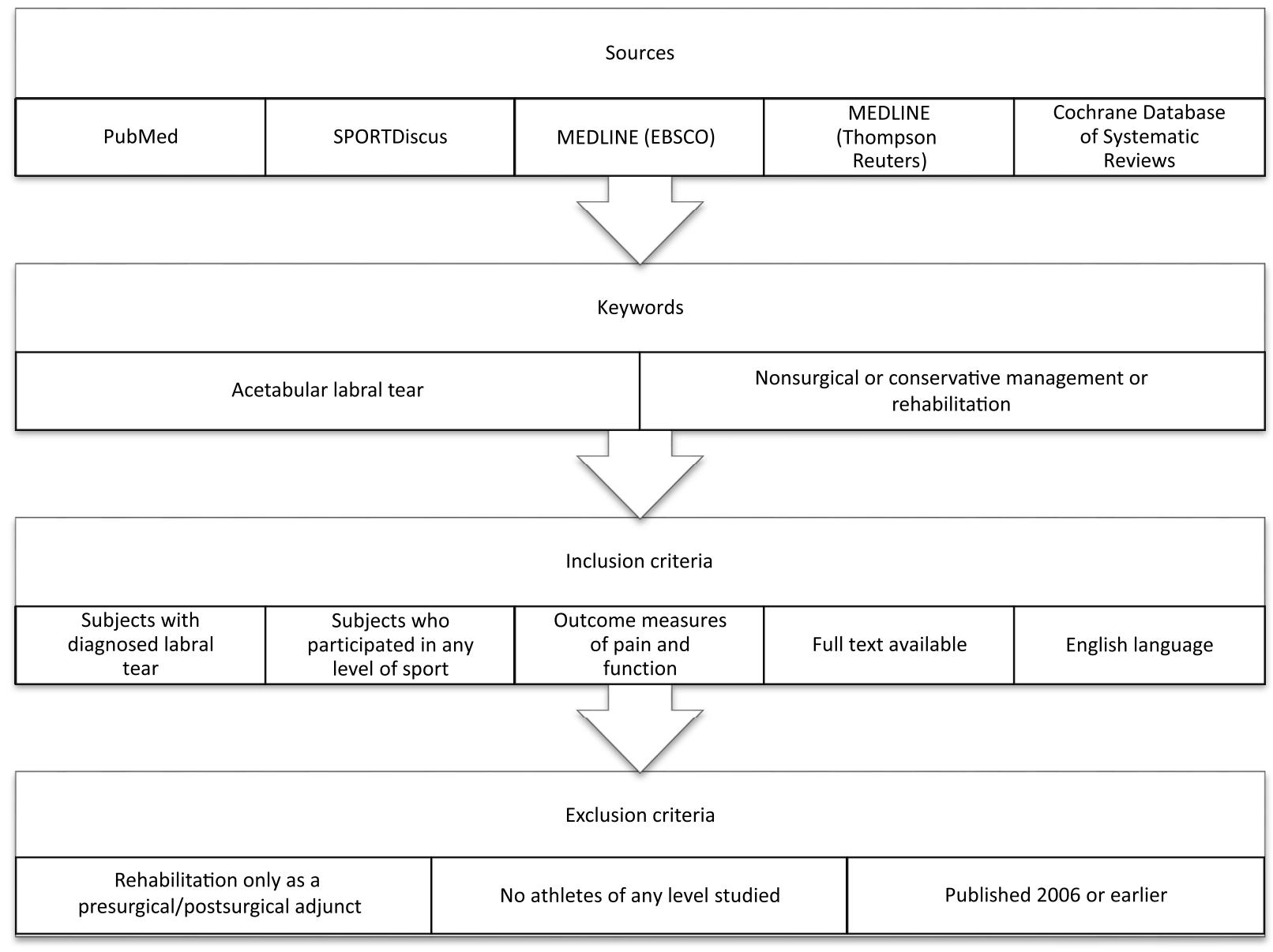

Figure 1 - Search strategy.

\section{Table 1 Summary of Study Designs of Articles} Retrieved

\begin{tabular}{llcl}
\hline $\begin{array}{l}\text { Level of } \\
\text { evidence }\end{array}$ & $\begin{array}{l}\text { Study } \\
\text { design }\end{array}$ & $\begin{array}{l}\text { Number } \\
\text { located }\end{array}$ & Reference \\
\hline 4 & Case series & 1 & $\begin{array}{l}\text { Yazbek et } \mathrm{al}^{6} \\
\text { Khoo-Summers and Bloom }\end{array}$ \\
5 & Case report & 3 & $\begin{array}{l}\text { Liem et al } \\
\text { MacIntyre et al }^{9}\end{array}$ \\
\hline
\end{tabular}

\section{Best Evidence}

All 4 studies were identified as the best available evidence due to their inclusion of athletic subjects and coverage of nonoperative treatment of acetabular labral tears. One article achieved a level 4 evidence grading according to Oxford Center for Evidence-Based Medicine criteria, whereas the other 3 studies were classified as level 5. The studies selected are summarized in Table 2.

\section{Implications for Practice, Education, and Future Research}

Three of the 4 studies located were case report designs, whereas the fourth study was a case series. Each study followed athletes ranging from the recreational to professional level who underwent rehabilitation with or without modalities to address symptoms and loss of function associated with an acetabular labral tear. Every patient discussed in the literature showed observable improvement in pain ratings measured by a visual analog or numerical pain rating scale, as well as improvement to overall function measured by ability to return to some level of sport, Nonarthritic Hip Score, Lequesne Hip Score, or other similar measure. Pain-free athletic activity was achieved in as little as 6 weeks and was shown to be sustained at a 1-year follow-up posttreatment. ${ }^{6-9}$ Four of the 6 athletes studied were able to return to their previous level of sport, including 2 professional, 1 nationally competitive, and 1 recreational athletes. ${ }^{6-}$ ${ }^{8}$ Another professional athlete had retired prior to the beginning of his conservative treatment but was able to return to participation at the recreational level. ${ }^{9}$ The remaining athlete's return to sport was not reported. ${ }^{6}$ No negative effects were reported in any case. No athlete studied was reported to elect surgery at a later date. In conclusion, the available literature agreed that nonsurgical treatment of acetabular labral tears produces favorable outcomes among athletes.

Unfortunately, the evidence presented is of low quality. Case report designs may include outliers, as the possibility of researcher bias in selecting which cases to publish is great. Case series designs lack controls and suffer from the skewing effects of a small sample size. It is imperative for future researchers to produce more robust studies, such as case-control or cohort designs, to ascertain whether 


\begin{tabular}{|c|c|}
\hline & Yazbek et al ${ }^{6}$ \\
\hline Study design & Case series \\
\hline Participants & $\begin{array}{l}\text { Four patients [aged } 27 \text { (male), } \\
24 \text { (male), } 24 \text { (female), and } 24 \\
\text { (male) y] with the history of } \\
\text { acetabular labral tear. The } \\
\text { patient aged } 27 \text { y (male) had } \\
\text { previously undergone a labral } \\
\text { repair surgery. The males were } \\
\text { athletes ranging from } \\
\text { recreational to professional } \\
\text { level, whereas the female was } \\
\text { sedentary. }\end{array}$ \\
\hline
\end{tabular}

Intervention investigated

All 4 patients underwent a 3-phase physical therapy protocol. Phase 1 addressed pain control, core stabilization, and movement pattern correction. Phase 2 focused on restoring ROM and correcting muscle strength imbalances. Phase 3 emphasized proprioception and sport-specific movement. Patients completed treatment within 9-16 wk depending on speed of progress.

Outcome measure

Main finding

Patients were evaluated for hip strength, range of motion, pain, and level of function. Instruments used included a handheld dynamometer, 8 special tests (Impingement, FABER, Scour, Internal Rotation, Squish, Lasegue, Piriformis, and Grava), a VAS, and the Lequesne Hip Score. Measurements were taken preintervention and at 4 and 6 mo posttreatment.

Following treatment, fewer special tests provoked pain in each patient. Each

participant's VAS pain score also dropped 4-7 points with 3 patients reporting no pain at follow-up. Lequesne Hip Scores simultaneously fell between 4 and 9 points each. Strength of the hip adductors, abductors, flexors, and extensors improved 0\%-98\% in the involved limb and $0 \%$ $139 \%$ in the uninvolved limb. One patient was able to return to professional jiu-jitsu competition. Other athletes return to sport were not remarked upon.
Khoo-Summers and Bloom $^{8}$

Case report

Subject was a 29 -y-old female, professional ballet dancer with a clinically diagnosed acetabular labral tear. She danced $36 \mathrm{~h} / \mathrm{wk}$ as a principal ballerina. Previously failed therapies included ice and medication.

The dancer was examined using a Sahrmann analysis to identify deficits in movement patterns believed to have contributed to her labral pathology. Identification of improper biomechanics directed corrective programming. The subject was prescribed posture education, 6 physical therapy sessions over $2 \mathrm{mo}$, and a home exercise program to address muscular control during sitting, standing, and walking, as well as dancing.

The patient was assessed using a numerical pain rating scale and a NHS both before and after the treatment. The patient was also questioned regarding pain during $\mathrm{ADL}$ and dance at both times.

The ice skater underwent a total of 4 mo of physical therapy beginning with sessions twice a week over $12 \mathrm{wk}$, as well as a daily home program, and ending with sessions once per week for the final 4 wk. Treatment goals addressed motor deficits found during her initial examination including poor core activation and weakness of the gluteus medius, external rotator, and paraspinal muscles, then progressed to related functional and sport-specific exercises.

The patient was assessed for pain using a VAS pretherapy and at $4 \mathrm{wk}, 6 \mathrm{wk}, 12 \mathrm{wk}$, $4 \mathrm{mo}$, and $1 \mathrm{y}$ postinjury. The patient's level of participation in figure skating was also recorded.

Prior to treatment, the patient reported pain after $30 \mathrm{~min}$ of sitting, 15 min of standing, or 5 min of walking rated at a 7 out of 10 , as well as a $36.25 \%$ NHS. Following treatment, the patient described pain as 0 out of 10 during ADLs and dance except mild groin pain during some advanced dance steps. Her NHS rose to $97.5 \%$, and she was able to return to her ballet career. The patient reported that she remained pain-free and dancing professionally $5 \mathrm{mo}$ posttreatment.
The patient reported initially reported an 8 out of 10 rating. This number was reduced at 4 wk of therapy, and pain was reported as 0 out of 10 from week 6 of therapy on. The patient rested from skating the first $6 \mathrm{wk}$ of therapy, was limited to step routines at $6 \mathrm{wk}$, was able to perform jumps to $75 \%$ of normal height at $12 \mathrm{wk}$, and returned to competition after 4 mo. She remained pain-free and nationally competitive $1 \mathrm{y}$ postinjury.

Maclntyre et al $^{\mathbf{9}}$

Case report

The patient was a 22-y-old male, retired professional hockey goalie with a confirmed acetabular labral tear, cam-type femoroacetabular impingement, and 4-y history of hip pain. The patient had recently retired from professional hockey due to (1) exclusion from surgical candidacy due to no trial of conservative treatment,

(2) surgical apprehension, and

(3) desire to preserve hip function.

Comprehensive, individualized, conservative treatment protocol including active release

technique, instrument-assisted soft tissue mobilization, spinal manipulation therapy, Mulligan mobilizations with movement, electroacupuncture, and

rehabilitation exercises.

Treatment was administered in 8 treatments over $6 \mathrm{wk}$. Exercises progressed from strength and stability builders to functional activities to sports-specific movements.

Pretreatment and posttreatment pain ratings were collected using a VAS. The patient was also evaluated using the Scour, FADIR, and FABER tests. The patient's ability to perform ADL and participate in hockey was recorded as well.

Scour, FADIR, and FABER tests produced positive results prior to treatment. At the 6-wk mark, tests were positive for a mechanical click, but no pain. The patient rated his pain as a 7 out of 10 prior to treatment. Pain was described as absent during ADL and exercise at $6 \mathrm{wk}$ after the commencement of therapy. Pain was absent during recreational hockey participation at $8 \mathrm{wk}$ and in competitive hockey at the time of publication. 
Table 2 (continued)

\begin{tabular}{|c|c|c|c|c|}
\hline & Yazbek et al ${ }^{6}$ & $\begin{array}{l}\text { Khoo-Summers and } \\
\text { Bloom }^{8}\end{array}$ & Liem et $\mathrm{al}^{7}$ & Maclntyre et al $^{9}$ \\
\hline $\begin{array}{l}\text { Level of } \\
\text { evidence }\end{array}$ & 4 & 5 & 5 & 5 \\
\hline $\begin{array}{l}\text { Validity score } \\
\text { (downs and } \\
\text { black) }\end{array}$ & 13 & N/A & N/A & N/A \\
\hline Conclusion & $\begin{array}{l}\text { A 3-phase physical therapy } \\
\text { program based on promoting } \\
\text { healthy movement patterns, } \\
\text { correcting hip strength } \\
\text { imbalances, and training } \\
\text { sensorimotor skills reduced } \\
\text { pain and increased hip } \\
\text { function in } 4 \text { subjects. } \\
\text { Nonsurgical intervention can } \\
\text { be effective in treating athletes } \\
\text { with acetabular labral tears. }\end{array}$ & $\begin{array}{l}\text { Identification and correction } \\
\text { of biomechanical errors } \\
\text { believed to cause a } \\
\text { professional ballerina's labral } \\
\text { tear allowed her to return to } \\
\text { full participation with minimal } \\
\text { symptoms. }\end{array}$ & $\begin{array}{l}\text { An individualized treatment } \\
\text { program based upon muscular } \\
\text { weaknesses of an adolescent } \\
\text { figure skater with an acetabular } \\
\text { labral tear allowed her to return } \\
\text { to national competition pain- } \\
\text { free within } 4 \text { mo of injury. } \\
\text { Technique development and } \\
\text { avoidance of irritating activity } \\
\text { were hypothesized to } \\
\text { contribute to the treatment's } \\
\text { success. It may be preferable to } \\
\text { attempt conservative } \\
\text { management prior to resorting } \\
\text { to surgery in the skeletally } \\
\text { immature athlete. }\end{array}$ & $\begin{array}{l}\text { A goalie who previously retired } \\
\text { from professional hockey due to } \\
\text { persistent symptoms of an } \\
\text { acetabular labral tear was able to } \\
\text { return to competitive hockey } \\
\text { pain-free following } 6 \text { wk of a } \\
\text { many-faceted conservative } \\
\text { treatment approach. } \\
\text { Conservative treatment should } \\
\text { be attempted prior to resorting to } \\
\text { surgery. When formulating } \\
\text { treatment regimen, the individual } \\
\text { aspects of a patient's pathology } \\
\text { must be considered, including } \\
\text { sport demands. }\end{array}$ \\
\hline
\end{tabular}

Abbreviations: ADL, activities of daily living; FABER, flexion, abduction, and external rotation; FADIR, flexion, adduction, and internal rotation; MRI, magnetic resonance imaging; N/A, not available; NHS, Nonarthritic Hip Score; ROM, range of motion; VAS, visual analog scale.

this type of treatment is effective on a larger scale and while controlling for more variables.

In the meantime, the risk in utilizing the methods suggested by this research is low. Conservative management is less invasive, less expensive, and less prone to complications than surgical alternatives. Positive outcomes include decreased pain, increased strength, increased function, and return to sport, up to and including previous levels. As such, nonsurgical treatment should be considered as the first option in treating acetabular labral tears. ${ }^{9}$

Implementation of the type of nonsurgical treatment plans discussed in this research requires a good deal of tailoring to each athlete. While most protocols followed the same general 3-phase template of (1) range of motion and strengthening, (2) functional movement, and (3) sport-specific exercise, individual biomechanical deficits were often implicated in the development of hip pathology and identified as the key to reducing symptoms..$^{7,8}$ This was especially apparent in the case of the ballerina, whose entire successful treatment was based upon a detailed movement analysis and correction rather than any generic rehabilitation exercises. ${ }^{8}$ This evidence supports the use of a sport-specific biomechanical evaluation, including hip stability and neuromuscular control to both direct treatment and measure progress. The ability to conduct this type of fine-tuned assessment is limited by the skill and experience of the attending clinician.

Furthermore, clinician experience with the sport in question could be another limiting factor for nonsurgical treatment. The diagnosis of acetabular labral tears appears to be concentrated within sports that demand extreme hip flexion, internal rotation, and adduction, such as dance and hockey. ${ }^{6,9}$ In the case of hockey, the butterfly technique used by some goalies has been implicated in the development of labral tears. ${ }^{9}$ Without knowledge of the demands of this technique, the clinician is limited in his or her ability to advise an athlete on biomechanical adjustments to be made. Further research into what other sport-specific movements produce destructive forces is warranted to promote injury prevention.

In conclusion, the use of nonsurgical rehabilitation to treat acetabular labral tears in athletes is justifiable due to support of low-level evidence, low risk of implementation, and the possibility of avoiding invasive surgery. Limitations for use include lack of high-level supporting evidence and clinician experience. Opportunities for further inquiry are endless due to the extremely limited amount of current research. Worthy areas of study include the application of nonsurgical rehabilitation to a larger population of injured athletes in a controlled setting, longitudinal studies, correlation studies between labral tear location/severity and success of nonsurgical treatment, and studies among various sports and levels of sport, to identify populations in which nonsurgical treatment may be more or less effective.

\section{References}

1. Bedi, A, Chen, N, Robertson, W, Kelly, BT. The management of labral tears and femoroacetabular impingement of the hip in the young, active patient. Arthroscopy. 2008;24(10):1135-1145. PubMed doi:10.1016/ j.arthro.2008.06.001

2. Boykin, RE, Patterson, D, Briggs, KK, Dee, A, Philippon, MJ. Results of arthroscopic labral reconstruction of the hip in elite athletes. Am J Sports Med. 2013;41(10):2296-2301. PubMed doi: 10.1177/0363546513498058

3. Byrd, JWT, Jones, KS. Hip arthroscopy in athletes: 10-year followup. Am J Sports Med. 2009;37(11):2140-2143. PubMed doi:10.1177/ 0363546509337705

4. Phillipon, MJ, Weiss, DR, Kuppersmith, DA, Briggs, KK, Hay, CJ. Arthroscopic labral repair and treatment of femoroacetabular impingement in professional hockey players. Am J Sports Med. 2010; 38(1):99-104. doi:10.1177/0363546509346393 
5. Singh, PJ, O'Donnell, JM. The outcome of hip arthroscopy in Australian Football League players: a review of 27 hips. Arthroscopy. 2010;26(6):743-749. PubMed doi:10.1016/j.arthro.2009. 10.010

6. Yazbek, PM, Ovanessian, V, Martin, RL, Fukuda, TY. Nonsurgical treatment of acetabular labral tears: a case series. J Orthop Sports Phys Ther. 2011;41(5):346-353. doi:10.2519/jospt.2011. 3225

7. Liem, BC, Loveless, MS, Apple, EL, Krabak, BJ. Nonoperative management of acetabular labral tear in a skeletally immature figure skater. PM R. 2014;6:951-955. PubMed doi:10.1016/j.pmrj.2014. 04.001

8. Khoo-Summers, L, Bloom, NJ. Examination and treatment of a professional ballet dancer with a suspected acetabular labral tear: a case report. Man Ther. 2015;20:623-629. doi:10.1016/j.math.2015. 01.015

9. MacIntyre, K, Gomes, B, MacKenzie, S, D’Angelo, K. Conservative management of an elite ice hockey goaltender with femoroacetabular impingement (FAI): a case report. J Can Chiropr Assoc. 2015;59(4): 398-409. PubMed 